\title{
Multicriteria Model for the Choice of Best Battery Provider
}

\author{
María Carmen Carnero* and Ana Belén López
}

\author{
University of Castilla-La Mancha, Spain
}

\begin{abstract}
The choice of suppliers is a matter of great importance in organizations. The cost, quality and delivery time provided to customers may depend to a large extent on this decision. This paper, therefore, describes a model applicable to a real organization, using multicriteria decision techniques to choose the best supplier of batteries. In order to establish concordance and discordance thresholds the values provided by the decision-maker of the company will be compared with those obtained by the fuzzy Analytic Hierarchy Process. Both valuations of the thresholds will be applied in the ELECTRE II technique.
\end{abstract}

Keywords: Supplier selection, ELECTRE II, Fuzzy Analytic Hierarchy Process, Concordance thresholds, Discordance thresholds.

\section{INTRODUCTION}

Considered the most important activity in the field of purchasing [1-2], the choice of suppliers has a decisive influence on the quality of goods and the optimization of material purchasing costs, helping to improve the performance of organizations and supply chains and corporate competitiveness [3].

Local suppliers have been substituted for global suppliers in recent decades, and so the complexity of choosing a supplier has increased. This complexity can be seen in the multiple factors to be assessed, some qualitative and some quantitative [4-6], which may in some cases conflict [3]. Due to its characteristics, therefore, Multi-Criteria Decision Making (MCDM) are ideal for this type of decision as they allow acceptable compromise solutions to found [7], which also facilitate public acceptance of the solutions obtained [8]. Furthermore, the choice of supplier depends largely on the assessment of the people in charge or the experts in each organization, and so it is a type of decision which includes such uncertainties as imprecision, fuzziness and incompleteness [9].

This has led to the literature applying MCDM in the choice of suppliers to increase considerably in recent decades. Nevertheless, there is a considerable increase in complexity incorporated into the application of the MCDM, which makes it more difficult to apply to real cases.

This paper sets out the process of supplier choice for a family of critical components, such as batteries, in

*Address correspondence to this author at the University of Lisbon, Instituto Superior Técnico, Avenida Rovisco Pais, 1, 1049-001 Lisbon, Portugal and University of Castilla-La Mancha, Technical School of Industrial Engineering, Avda. Camil José Cela s/n, 13071 Ciudad Real, Spain; Tel: +34 (9)26 295300;

Fax: +34 (9)26 295361; E-mail: carmen.carnero@uclm.es the manufacture of the product. This will be done by applying the ELimination Et Choix Traduisant la REalitè II (ELECTRE II) and Fuzzy Analytic Hierarchy Process (FAHP) techniques. FAHP will be used to account for the uncertainty which characterizes the establishment of concordance and discordance thresholds in the ELECTRE II technique. The results of the concordance and discordance thresholds provided directly by the decision centre are to be compared with those obtained by applying FAHP. The model proposed solves a real problem in an emergency lighting company and gives a different view with respect to the currently applied methodologies, more complex but also more difficult to apply to real situations.

The paper is organized as follows. First, there is a literature review about supplier selection in MCDM and especially in relation to outranking methods. Next, the ELECTRE II technique is described. Then a battery supplier selection model is described. Finally, the findings are discussed, followed by general conclusions.

\section{BACKGROUND}

Sonmez (2006) [10] defines supplier selection as the process of finding suppliers able to provide the buyer with the requisite quality of products and services at the right quality and price and at the right moment. This process generally has the following stages [11]:

- Identification of the need for a new supplier

- Identification and definition of criteria.

- $\quad$ Assessment of potential suppliers.

- $\quad$ Final supplier selection.

To which can be added a continuous evaluation and assessment of selected suppliers [5]. 
The criteria used for supplier selection depends on the specific organization taking the decision, since the organizational structure, management strategy, enterprise culture, etc., are specific aspects of each organization which will affect the selection criteria [9].

Chai et al. (2013) [12] perform a literature review on supplier selection determining three types of methodology present in the contributions: Multi-Criteria Decision Making (MCDM) techniques, Mathematical Programming (MP) techniques, and Artificial Intelligence (AI) techniques. With respect to MCDM, different techniques have been used with the categories of multi-attribute utility methods (for example Analytic Hierarchy Process (AHP) and Analytic Network Process (ANP)), outranking methods (such as Elimination and Choice Expressing Reality (ELECTRE) and the Preference Ranking Organization Method for Enrichment Evaluation (PROMETHEE)); compromise methods (for example the Technique for Order Performance by Similarity to Ideal Solution (TOPSIS) and the Multicriteria Optimization and Compromise Solution (VIKOR)), and other MCDM techniques among which the Simple Multi-attribute Rating Technique (SMART) and Decision-Making Trial and Evaluation Laboratory (DEMATEL) stand out. The study shows how the multicriteria techniques are mainly applied to this type of problem.

AHP is the multicriteria technique mainly applied to supplier selection [13] (examples of its application may be seen in [14-24]. Nevertheless, using AHP accepts absolute compensation between the different criteria, which can lead to unrealistic results [25]. Furthermore, in some real problems full comparability between two alternatives cannot be considered [26].

However, outranking methods are only partially compensatory and are capable of dealing with situations in which imprecision is present [26]. Both characteristics should be included in the supplier selection problem, but this has not been considered in the literature [26]. The application of outranking methods to supplier selection is seen to be suited to the characteristics of this type of decision, being ranking problems, with the presence of qualitative as well as quantitative evaluation criteria, not fully compensatory decision logic, uncertainty and imprecision deriving from inaccurate data, incomplete agreement of decision-makers on preferences and importance of criteria [25]. According to Roy [27], the ELECTRE family method takes into account ambiguity, that is, when information is unclear or there are conflicting interpretations.

The family of ELECTRE methods includes the ELECTRE I, ELECTRE II, ELECTRE III, ELECTRE IV, ELECTRE IS, ELECTRE TRI, with the variants ELECTRE TRI-C and ELECTRE TRI-NC, and ELECTRE ${ }^{\text {GKMS }}$.

The ELECTRE II method has been extensively used in real-world decision problems, proving its utility; For example, Duckstein and Gershon (1983) [28] use ELECTRE II to produce a complete ranking of vegetation management scheme alternatives. [29] use it to choose a solid waste management system in a region of Finland. Huang and Chen (2005) [30] apply ELECTRE II to choose the best option for the redevelopment of land in Keelung Harbor in Taiwan. [31] show how Multi-Criteria Decisions and CaseBased Reasoning are complementary, and they have developed an application for wire forming machines using ELECTRE I and II. Huang and Ke (2012) [32] use ELECTRE-II together with exponential utility functions to choose the best construction enterprise. Jun et al. (2014) [33] use ELECTRE II to select the site of wind/solar hybrid power station.

Among the contributions that apply outranking techniques to the choice of suppliers, the following are especially worthy of note. De Boer et al. (1998) [26] apply ELECTRE I to the choice between five suppliers considering the criteria cost level, quality image, geographical distance and yearly turnover. HatamiMarbini and Tavana (2011) [34] apply fuzzy ELECTRE I method to consider the uncertain, imprecise and linguistic assessment provided by a decision-making group to select the most suitable materials supplier in a high-technology manufacturing company from an example described by [1]. From the models described by [1] and [34], Chen (2014) [35] develops an ELECTRE methodology for multiple criteria group decision-making within the environment of interval type-2 fuzzy trapezoidal fuzzy numbers. In all cases the profitability of the supplier, closeness of relationship, technological capability, conformance quality and conflict resolution are considered as criteria. Almeida (2007) [36] uses ELECTRE and utility functions when outsourcing vendor selection; to do this cost and quality of service for each alternative; the latter includes probable delivery time and confidence in quality commitment. Montazer et al. (2009) [37] use a fuzzy version of ELECTRE III for a vendor selection process in an oil industry. [38] use ELECTRE to compare the 
crisp and fuzzy environments for supplier selection in a manufacturing company in Turkey. [39] use an improved ELECTRE III method and entropy weight for supplier selection in supply chains. Gómez and Carnero (2011) [40] use ELECTRE II to choose the best supplier of a Computerised Maintenance Management System in a Regional Health Service. They apply a two-stage methodology: in the first stage, software suppliers are chosen who can guarantee the successful introduction of the software, and then the computer programme is chosen which best satisfies the requirements of the organization.

The field of logistics and transportation, which includes supplier selection, is one of the first areas to which PROMETHEE was applied [41]. Dulmin and Mininno (2003) [25] describe a model for supplier selection in a public rail transportation organization. This model includes the criteria mark-up, processing time, prototyping time, design revision time, quality system, co-design and technological levels in the PROMETHEE technique. Araz and Ozkarahan (2007) [42] developed a new multicriteria method based on PROMETHEE for effective strategic sourcing and evaluating supplier participation during product development. The following criteria were considered: support in product structural design, support in process design and engineering, design revision time, prototyping time, level of technology, quality performance, financial strength, cost reduction performance, delivery performance and ease of communication. The methodology classifies suppliers by categories: strategic partners, the promising suppliers which are possible candidates for supplier development programs, competitive suppliers and the suppliers to be pruned. In [43] PROMETHEE is used together with fuzzy goal programming to assess the most suitable outsourcers to be strategic partners of a textile company, and also allocates the quantities to be ordered from them.

The number of contributions applying ELECTRE II has increased recently, despite being one of the oldest versions of the outranking methods [44], which proves its current worth.

\section{ELECTRE II METHODOLOGY}

ELECTRE II [45] allows a complete ordinal ranking of alternatives to be obtained from a set of criteria. ELECTRE II in carried out in two stages: one to obtain the outranking graphs and another to calculate three different types of classification of alternatives [46].
ELECTRE II requires the following information: a set of criteria, a set of alternatives, assessment of each alternative according to each criterion, the weightings of the criteria, and the concordance and discordance thresholds [40].

In ELECTRE methods, preferences are defined by means of binary outranking relations, $S$, whose significance is at least as good. An outranking relation is based on two concepts:

- Concordance. This expresses the relative importance of the criteria in which an alternative $i$ is preferable to another $j$. A sufficient number of criteria should be in favour of the assertion $i$ is preferred to $j$.

- Non-discordance. None of the criteria in the minority should oppose too strongly the statement $i$ is preferred to $j$.

$i$ outranks $j$ (iSj) if the concordance and nondiscordance conditions are satisfied simultaneously.

In the case of the concordance condition for two alternatives $(i, j)$ the concordance index is defined:

$C(i, j)=\frac{P^{+}(i, j)+P^{=}(i, j)}{P^{+}(i, j)+P^{=}(i, j)+P^{-}(i, j)} \geq \alpha$

where $P^{+}(i, j)$ is the sum of the weights of the criteria for which alternative $i$ is preferable to alternative $j$; $P^{=}(i, j)$ is the sum of the weights of the criteria of the case where alternative $i$ is equal to alternative $j$; and $P^{-}(i, j)$ is the sum of the weights of the criteria for which alternative $j$ is preferable to $j . \alpha$ is an acceptable concordance limit level, generally set at 0.5 [28].

Gathering the concordance indices for all the pairs of alternatives $(i, j)$ gives the concordance matrix.

For the non-discordance condition, for the criteria in which alternative $j$ is preferable to alternative $i$, the difference between the assessment of the two alternatives must not be significant. The discordance index can be calculated from Equation (2).

$D(i, j)=\operatorname{Max}\left[\frac{g_{k}(j)-g_{k}(i)}{g_{k}^{+}-g_{k}^{-}}\right] \forall k$ where $g_{k}(j)>g_{k}(i)$

Where, $g_{k}(i)$ is the valuation of alternative $i$ for criterion $k, g_{k}(j)$ is the valuation of alternative $j$ for 
criterion $k, g_{k}^{+}$is the best degree of valuation obtained for criterion $k$ and $g_{\bar{k}}^{-}$is the worst degree of valuation obtained for criterion $k$. To facilitate this process, the valuations of the alternatives in each criterion are usually normalized so that $g_{k}^{+}=1$ and $g_{k}^{-}=0$. Although other values will be used, in our case we will use $g_{k}^{+}=10$ and $g_{k}^{-}=0$.

The decision-maker must define [47] three concordance thresholds (high, medium and low) called $\alpha^{+}, \alpha^{0}$ and $\alpha^{-}$. They should meet the following conditions:

$0 \leq \alpha^{-}<\alpha^{0}<\alpha^{+} \leq 1$

Additionally, two increasing discordance thresholds have to be defined and must satisfy the conditions:

$0 \leq d^{0}<d^{+} \leq 1$

With these five thresholds, two types of outranking relations are possible [31]:

- $\quad$ Strong outranking $\left(\mathrm{iO}_{\mathrm{s}} \mathrm{j}\right)$ :

$$
\left\{\begin{array} { l } 
{ \frac { P ^ { + } ( i , j ) } { P ^ { - } ( i , j ) } \geq 1 ; } \\
{ C _ { i j } \geq \alpha ^ { + } , \text { and } } \\
{ \frac { g _ { k } ( j ) - g _ { k } ( i ) } { g _ { k } ^ { + } - g _ { k } ^ { - } } \leq d ^ { + } \forall k \in F }
\end{array} \text { or } \left\{\begin{array}{l}
\frac{P^{+}(i, j)}{P^{-}(i, j)} \geq 1 ; \\
\frac{C_{i j} \geq \alpha^{0}, \text { and }}{g_{k}^{+}-g_{k}^{-}} \leq d^{0} \forall k \in F
\end{array}\right.\right.
$$

- Weak outranking $\left(\mathrm{iO}_{\mathrm{wj}} \mathrm{j}\right)$ :

$$
\left\{\begin{array}{l}
\frac{P^{+}(i, j)}{P^{-}(i, j)} \geq 1 ; \\
C_{i j} \geq \alpha^{-} \text {, and } \\
\frac{g_{k}(j)-g_{k}(i)}{g_{k}^{+}-g_{k}^{-}} \leq d^{+} \forall k \in F
\end{array}\right.
$$

If a binary relation exists on set $X$ it is possible to build a graph $G=(V, U)$, where $V$ is the set of vertices and $U$ the set of arcs. For each alternative $i \in \mathrm{X}$ we associate a vertex $\mathrm{V} \in \mathrm{V}$ and for each pair of alternatives $(i, j) \in X$ the arc $(\mathrm{v}, \mathrm{w})$ exists either if $i$ is strictly preferred to $j(\mathrm{iPj})$ or $\mathrm{a}$ is indifferent to $\mathrm{b}(\mathrm{i} I \mathrm{j})$. An alternative $i$ outranks $j$ if and only if the $\operatorname{arc}(\mathrm{v}, \mathrm{w})$ exists [48]. It is necessary to construct a strong point graph based on the strong outranking relations and a weak point graph based on weak outranking relation.

It is possible to make the following types of ranking [46]:

- $\quad$ Forward or direct ranking $R_{\text {forward }}(i)$. This considers the number of outranking relations entering in each alternative; an entering outranking relation of alternative $j$ is the subset of alternatives $(1,2, \ldots, m)$ such that each strongly classifies the one following and ends with the alternative analysed $\left(1 \mathrm{O}_{\mathrm{s}} 2,2 \mathrm{O}_{\mathrm{s}} 3, \ldots, \mathrm{m}-1 \mathrm{O}_{\mathrm{s}} \mathrm{m}\right.$, $\left.m \mathrm{O}_{s} \mathrm{~s}\right)$. The length of this path is the number of arcs that it contains; if several entering outranking relations exist, the relations with the highest number of arcs should be selected. The weak outranking relations are only considered in the case of a tie.

- Reverse or inverse ranking $R_{\text {reverse }}(i)$. This considers the number of outranking relations leaving the alternative; a leaving outranking relation of alternative $j$ is the subset of alternatives $(1,2, \ldots, m)$ such that each one is strongly classified by the previous alternative $\left(j \mathrm{O}_{\mathrm{s}} 1,1 \mathrm{O}_{\mathrm{s}} 2, \ldots, \mathrm{m}-1 \mathrm{O}_{\mathrm{s}} \mathrm{m}\right)$; the length of the leaving outranking relation is the number of arcs that it contains and the longest arch should be selected.

- Median or intermediate ranking $R_{\text {median }}(i)$. The final ranking of alternative $i$ is calculated, as suggested by Roy and Bertier (1973) [45], from equation (5).

$R_{\text {median }}(i)=\frac{R_{\text {forward }}(i)+R_{\text {reverse }}(i)}{2}$

\section{MULTICRITERIA MODEL FOR THE CHOICE OF BEST BATTERY PROVIDER}

The organization that was the subject of this research is an outstanding leader in Europe in emergency lighting. Its main goals are excellence in the quality of its products, and design and innovation. This leads the company to pursue a policy of continuous improvement.

The aim of this study is to choose the best battery supplier for the purchasing department. The study focuses on this family of products for the following reasons: 
- Batteries represent the highest cost for the department.

- In Spain there are no suppliers which manufacture batteries. They must depend on distributers.

- The idea is to develop a global operations strategy and so to find international suppliers who can adapt to the characteristics and requirements of the company is essential to increase competitiveness.

- $\quad$ Currently purchasing of material is carried out by open bidding on the Internet, making the relationship with suppliers short term. The idea is to encourage long-term relations with a single supplier.

The multicriteria ELECTRE II, and ELECTRE II combined with FAHP, will be used to do this.

\section{Structuring}

To make the choice of supplier the following decision criteria were considered by the decision maker:

- Cost. This is considered to be the price of purchasing the material in question. This includes the buying expenses up to reception of the goods by the company. When modifications in the values registered are authorized, by reason of law, these modifications and their economic consequences for the financial situation of the organization should be communicated to the users of the accounting information. In all cases the duty paid should be included. The result is based on the price per unit once the product is in the warehouse.

- $\quad$ Method of payment. There are at least four forms of payment which guarantee security and confidentiality, which are now listed: bank transfer, payment on delivery, credit cards and postal giro by a contracted transportation firm. In the case under analysis only one form of payment is considered, bank transfer, which is distinguished from the other alternatives by the days available to make it.

- Response to Urgent Need. This refers to the attitude of the supplier to any change, either at the last minute or because of bad planning when assigning a new, unexpected but very urgent, order.

- $\quad$ History with the Supplier. This is considered to be the time that the company has been operating, negotiating on a common level, with the supplier, a criterion that can bring confidence and security to the company.

- $\quad$ Average Delivery Time. This is the average time the supplier takes to fulfil the order.

- Response Capability. This is defined as the capacity that different suppliers have to respond to the changing conditions of quantity, volume, specifications, etc., of the orders they receive.

- Percentage of Rejections. This refers to the specified quality. This quality is measured once the product is in the warehouse and is verified by the Quality Department. Rejection may be due to damage to the product, not meeting the stated specifications, or other reasons. This criterion is determined as a function of the number of batteries rejected in the number of orders made.

\section{Weighting}

Weighting of the criteria is not a direct or trivial matter; the importance of the criteria includes the subjectivity of the decider, which means the assessments must have a minimum concordance between the valuations.

Assigning weights to the criteria was done by the decision-maker, in this case the Purchasing Manager of the organization. They were given several days to reflect so as to have the most objective data, and the weightings thus obtained are set out in Table 1.

\section{The assigning of values to each alternative}

Six alternatives or suppliers are assessed, but due to its policy of privacy, the Purchasing Department of the company felt if appropriate to give only codes corresponding to the companies which were subject to analysis.

The values assigned to each alternative in each criterion are set out in Table 1. It can be seen that the criteria there are both quantitative and qualitative. The information about the qualitative criteria was provided by the Purchasing Manager of the company, who thus acts as the decision centre. This is because for the 
Table 1: Valuations of the Alternatives

\begin{tabular}{|c|c|c|c|c|c|c|c|}
\hline Suppliers & Cost $(€)$ & $\begin{array}{c}\text { Payment } \\
\text { method } \\
\text { (days) }\end{array}$ & $\begin{array}{c}\text { Response to } \\
\text { urgent need }\end{array}$ & $\begin{array}{c}\text { History with the } \\
\text { supplier (years) }\end{array}$ & $\begin{array}{c}\text { Average delivery } \\
\text { time (days) }\end{array}$ & $\begin{array}{c}\text { Response } \\
\text { capability }\end{array}$ \\
\hline \hline BSP & 0.752 & 90 & Very High & 7 & 7 & Medium \\
rejections (\%)
\end{tabular}

criteria Response to Urgent Need and Response Capability there are no historical records. The manager of the Quality Department gave the percentage of defective products associated with each supplier, while the Purchasing Manager provided data on cost, payment method, response to urgent need, history with the supplier and response capability.

Normalization was performed first, to turn the scales and units of the different criteria into a common scale so as to be comparable across the criteria. This was done by assessing the type of scale of each criterion, direct (benefit type criterion) or inverse (cost type criterion), to then use the proportional method. A scale with a range from zero to 10 has been used for all criteria. The data from the different criteria can then be compared as they now use similar scales. The results obtained are shown in Table 2. It can be seen that there is no best alternative nor one which is weakest.

Applying the ELECTRE II method gives the matrix $\mathrm{Pij}^{+} / \mathrm{Pij}$ shown in Table 3 . The concordance and discordance matrices are shown in Tables 4 and $\mathbf{5}$ respectively.

\section{Concordance and discordance thresholds}

The values of the concordance and discordance thresholds assigned directly by the decision-maker were $\alpha^{+}=0.9, \alpha^{0}=0.65, \alpha^{-}=0.55, d^{0}=0.4$ and $d^{+}=0.8$.

Table 2: Normalized Valuation of the Suppliers

\begin{tabular}{|c|c|c|c|c|c|c|c|}
\hline Suppliers & Cost & $\begin{array}{c}\text { Payment } \\
\text { Method }\end{array}$ & $\begin{array}{c}\text { Response to } \\
\text { Urgent Need }\end{array}$ & $\begin{array}{c}\text { History with } \\
\text { Supplier }\end{array}$ & $\begin{array}{c}\text { Average Delivery } \\
\text { Time }\end{array}$ & $\begin{array}{c}\text { Response } \\
\text { Capability }\end{array}$ & $\begin{array}{c}\text { Percentage of } \\
\text { Rejections }\end{array}$ \\
\hline \hline BSP & 8.0585 & 10.0000 & 10.0000 & 6.3636 & 10.0000 & 6.6666 & 10.0000 \\
\hline ASP & 7.2143 & 10.0000 & 7.5000 & 10.0000 & 2.3333 & 10.0000 & 10.0000 \\
\hline CSP & 7.9216 & 10.0000 & 5.0000 & 6.3636 & 7.0000 & 3.3333 & 8.8544 \\
\hline DSP & 6.7333 & 10.0000 & 2.5000 & 3.6364 & 0.7778 & 3.3333 & 10.0000 \\
\hline BCH & 10.0000 & 3.3333 & 7.5000 & 0.4545 & 1.1667 & 10.0000 & 8.8498 \\
\hline CCH & 9.4688 & 2.0000 & 2.5000 & 0.4545 & 0.7778 & 6.6666 & 10.0000 \\
\hline
\end{tabular}

Table 3: Matrix Pij $/ \mathbf{P i j}$

\begin{tabular}{|c|c|c|c|c|c|c|}
\hline $\mathbf{P}_{\mathrm{ij}}{ }^{+} \mathbf{P}_{\mathrm{ij}}{ }^{-}$ & BSP & ASP & CSP & DSP & BCH & \multicolumn{1}{c|}{$\mathbf{C C H}$} \\
\hline \hline $\mathrm{BSP}$ & - & 3.4286 & 0.910 & 0.775010 & 1.8571 & 2.5000 \\
\hline $\mathrm{ASP}$ & 0.2917 & - & 1.0556 & 0.775010 & 2.5000 & 3.2500 \\
\hline $\mathrm{CSP}$ & 0.0000 & 0.9474 & - & 4.1667 & 1.0000 & 1.0000 \\
\hline $\mathrm{DSP}$ & 0.0000 & 0.0000 & 0.2400 & - & 0.3333 & - \\
\hline $\mathrm{BCH}$ & 0.5385 & 0.4000 & 1.0000 & 3.0000 & 3.5000 \\
\hline $\mathrm{CCH}$ & 0.4000 & 0.3077 & 1.0000 & 3.5000 & 0.1818 & - \\
\hline
\end{tabular}


Table 4: Concordance Matrix

\begin{tabular}{|c|c|c|c|c|c|c|}
\hline $\mathbf{C}_{\mathrm{ij}}$ & BSP & ASP & CSP & DSP & BCH & CCH \\
\hline \hline BSP & - & 0.8250 & 1.0000 & 1.0000 & 0.6500 & 0.8000 \\
\hline ASP & 0.4000 & - & 0.5500 & 1.0000 & 0.8000 & 0.8000 \\
\hline CSP & 0.1000 & 0.5250 & - & 0.8500 & 0.5000 & 0.5000 \\
\hline DSP & 0.2250 & 0.2250 & 0.3750 & - & 0.2500 & 0.6500 \\
\hline BCH & 0.3500 & 0.5000 & 0.5000 & 0.7500 & - & 0.8500 \\
\hline CCH & 0.5000 & 0.3500 & 0.6500 & 0.9000 & 0.1750 & - \\
\hline
\end{tabular}

Table 5: Discordance Matrix

\begin{tabular}{|c|c|c|c|c|c|c|}
\hline $\mathbf{D}_{\mathrm{ij}}$ & BSP & ASP & CSP & DSP & BCH & CCH \\
\hline \hline $\mathrm{BSP}$ & - & 0.3636 & 0.0000 & 0.0000 & 0.3333 & 0.1410 \\
\hline $\mathrm{ASP}$ & 0.7667 & - & 0.4667 & 0.0000 & 0.2786 & 0.2255 \\
\hline $\mathrm{CSP}$ & 0.5000 & 0.6667 & - & 0.1146 & 0.6667 & 0.3333 \\
\hline $\mathrm{DSP}$ & 0.9222 & 0.6667 & 0.6222 & - & 0.6667 & 0.3333 \\
\hline $\mathrm{BCH}$ & 0.8833 & 0.9546 & 0.6667 & 0.6667 & - & 0.1150 \\
\hline $\mathrm{CCH}$ & 0.9222 & 0.9546 & 0.8000 & 0.8000 & 0.5000 & - \\
\hline
\end{tabular}

Given that the thresholds are strongly subjective [49] and establishing them carries uncertainty, FAHP is used to set these thresholds, as an alternative method. FAHP takes into account uncertainties and ambiguities in judgements or values given by decision makers.

A triangular fuzzy number is defined as $\tilde{a}=(l, m, u)$, where $l$ and $u$ are the lower and upper limits and $m$ is the modal value. The following condition should be met: $l \leq m \leq u$. A membership function is defined by Chang (1996) [50] according to equation (6).

$\mu(x)=\left\{\begin{array}{l}\frac{x}{m-l}-\frac{l}{m-l} x \in[l, m] \\ \frac{x}{m-u}-\frac{u}{m-u} x \in[m, u] \\ 0 \quad \text { otherwise }\end{array}\right.$

The operational laws of triangular fuzzy numbers $\tilde{a}_{1}=\left(l_{1}, m_{1}, u_{1}\right)$ and $\tilde{a}_{2}=\left(l_{2}, m_{2}, u_{2}\right)$ are [51]:

$\left(l_{1}, m_{1}, u_{1}\right) \oplus\left(l_{2}, m_{2}, u_{2}\right)=\left(l_{1}+l_{2}, m_{1}+m_{2}, u_{1}+u_{2}\right)(7)$

$\left(l_{1}, m_{1}, u_{1}\right) \otimes\left(l_{2}, m_{2}, u_{2}\right) \approx\left(l_{1} l_{2}, m_{1} m_{2}, u_{1} u_{2}\right)$

$\left(l_{1}, m_{1}, u_{1}\right)^{-1} \approx\left(\frac{1}{u_{1}}, \frac{1}{m_{1}}, \frac{1}{l_{1}}\right)$

A represents a fuzzified reciprocal matrix with the pairwise comparisons between the element $i$ and $j \mathrm{i}, \mathrm{j}$ $\in\{1,2, \ldots, n\}$.

$$
\tilde{A}=\left(\begin{array}{cccc}
(1,1,1) & \tilde{a}_{12} & \ldots & \tilde{a}_{1 n} \\
\tilde{a}_{12} & (1,1,1) & \ldots & \tilde{a}_{2 n} \\
\cdot & \cdot & \ldots & \cdot \\
\cdot & \cdot & \ldots & \cdot \\
\tilde{a}_{n 1} & \tilde{a}_{n 2} & \ldots & \ldots(1,1,1)
\end{array}\right)
$$

To perform the judgments or pairwise comparisons between the thresholds, the fuzzy scale shown in Table 6 is used.

Table 6: Fuzzy Linguistic Scale

\begin{tabular}{|c|c|}
\hline Preference of pairwise comparisons & Fuzzy scale \\
\hline \hline Just equal & $(1,1,1)$ \\
\hline Very weakly more important & $(1 / 2,1,3 / 2)$ \\
\hline Weakly more important & $(1,3 / 2,2)$ \\
\hline Moderately more important & $(3 / 2,2,5 / 2)$ \\
\hline Strongly more important & $(2,5 / 2,3)$ \\
\hline Absolutely more important & $(5 / 2,3,7 / 2)$ \\
\hline
\end{tabular}

The procedure developed by [50] and shown in Figure 1 was used to apply FAHP.

The results obtained for the concordance thresholds are: $\alpha^{+}=1, \alpha^{0}=0.789$ and $\alpha^{-}=0.639$. In this case, the results were not normalized, in order to retain significance within the ELECTRE II method. A similar 


\section{THE PROCEDURE FOR APPLYING FAHP}

Step 1. Construct the hierarchy structure of the decision problem.

Step 2. The fuzzy Judgments matrix $\widetilde{A}$ is obtained by means of pairwise comparisons of criteria at the same level of hierarchy.

Step 3. The value of fuzry synthetic extent $\widetilde{S}_{i}$ with respect to the L-object is defined

$$
\widetilde{S}_{i}=\sum_{j=1}^{m} \widetilde{a}_{i j} \otimes\left[\sum_{i=1}^{n} \sum_{j=1}^{m} \widetilde{a}_{i j}\right]^{-1}
$$

Step 4. The values of $\widetilde{S}_{i}$ are compared and the degree of possibility of $\widetilde{S}_{j}=\left(l_{j}, m_{j}, u_{j}\right) \geq$ $\widetilde{S}_{i}=\left(l_{i}, m_{i}, u_{i}\right)$ is calculated

$$
V\left(\widetilde{S}_{j} \geq \widetilde{S}_{i}\right)=\left\{\begin{array}{lr}
1, & \text { if } m_{j} \geq m_{i} \\
0, & \text { if } l_{i} \geq u_{j} \\
\frac{l_{i}-u_{j}}{\left(m_{j}-u_{j}\right)-\left(m_{i}-l_{i}\right)}, & \text { otherwise }
\end{array}\right.
$$

Step 5. The minimum degree possibility of $V\left(\widetilde{S}_{j} \geq \widetilde{S}_{i}\right)$ is calculated for $i, J=1,2, \ldots, k$.

$V\left(\widetilde{S} \geq \widetilde{S}_{1}, \widetilde{S}_{2}, \ldots, \widetilde{S}_{k}\right)=V\left(\widetilde{S} \geq \widetilde{S}_{1}\right)$ and $V\left(\widetilde{S} \geq \widetilde{S}_{2}\right)$ and $\ldots V\left(\widetilde{S} \geq \widetilde{S}_{k}\right)=\min V\left(\widetilde{S} \geq \widetilde{S}_{i}\right)$ The weight vector is $\left.W^{\prime}=\left(\min V\left(\widetilde{S} \geq \widetilde{S}_{1}\right), \min V\left(\widetilde{S} \geq \widetilde{S}_{2}\right), \ldots, \min V\left(\widetilde{S} \geq \widetilde{S}_{k}\right)\right)\right)^{T}$

Step 6. The weight vector is normalized, giving the non-fuzzy weight vector $w$.

Figure 1: Procedure for applying fuzzy AHP.

procedure was followed with the discordance thresholds, giving $d^{0}=0.316$ and $d^{+}=0.684$. The consistency ratio of the pairwise comparison matrices provided by the decision maker are lower than 0.1 , and so the judgements are consistent.

\section{RESULTS}

With the judgements given directly by the decisionmaker the strong and weak outranking graphs were obtained, as shown in Figure 2.

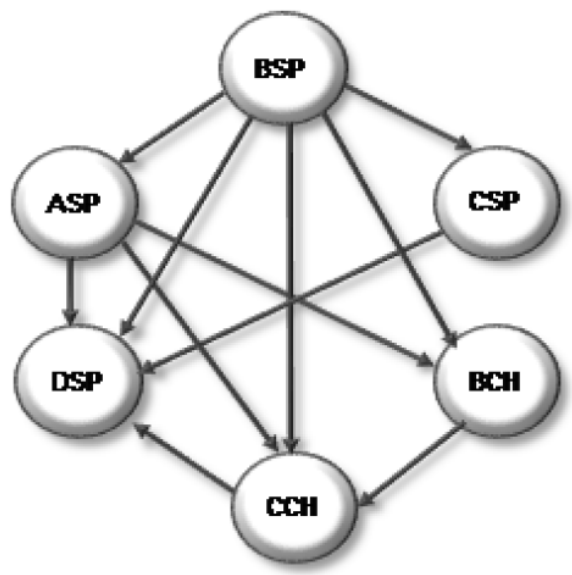

Figure 3 shows the strong and weak outranking graphs obtained by applying the concordance and discordance thresholds via FAHP.

The direct, inverse and intermediate classifications, with the thresholds set directly by the decision centre, and using FAHP, are shown in Tables $\mathbf{7}$ and $\mathbf{8}$ respectively.

The results show that the classification of alternatives using thresholds obtained by the two

Figure 2: Outranking graphs: Strong outranking graph (left); Weak outranking graph (right). 

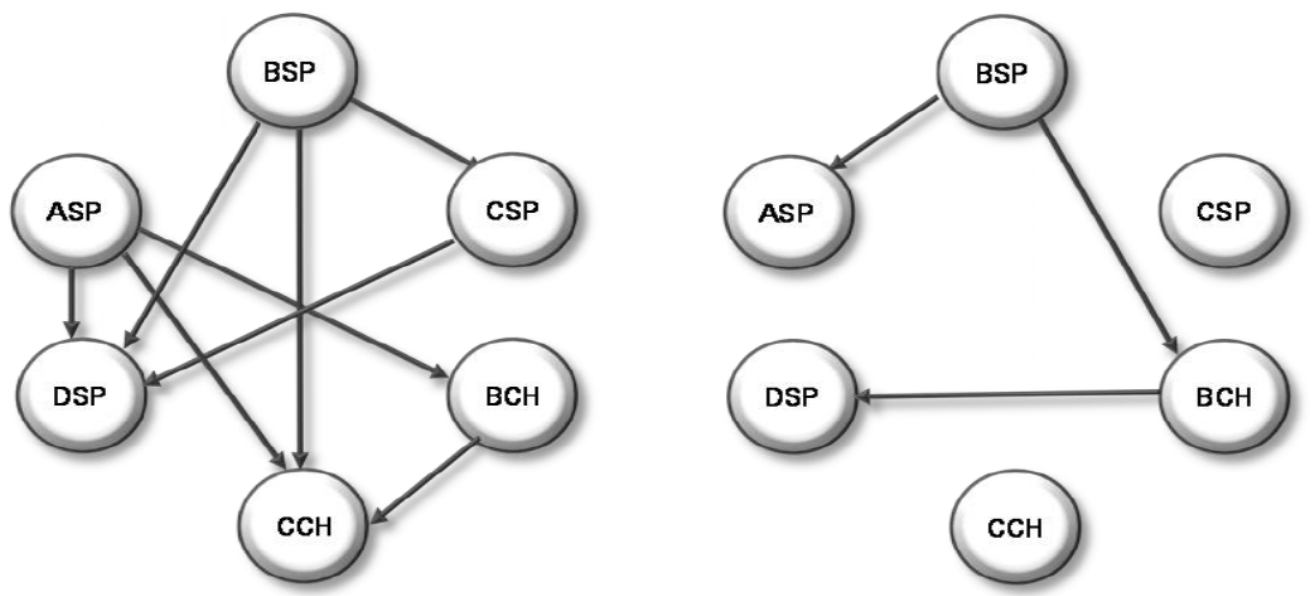

Figure 3: Outranking graphs using FAHP thresholds: Strong outranking graph (left); Weak outranking graph (right).

Table 7: Results in Different Types of Ranking

\begin{tabular}{|c|c|c|c|}
\hline Alternatives & Direct ranking & Inverse ranking & Intermediate ranking $^{1^{\text {st }}}$ \\
\hline \hline BSP & $1^{\text {st }}$ & $1^{\text {st }}$ & $2^{\text {nd }}$ \\
\hline ASP & $2^{\text {nd }}$ & $2^{\text {nd }}$ & 4 th \\
\hline CSP & $3^{\text {rd }}$ & 5 th & 5 th \\
\hline DSP & 6 th & 6 th & $3^{\text {rd }}$ \\
\hline$B C H$ & 4 th & $3^{\text {rd }}$ & 4 th \\
\hline CCH & 5 th & 4 th & \multicolumn{2}{|c|}{} \\
\hline
\end{tabular}

Table 8: Results in Different Types of Ranking Using FAHP Thresholds

\begin{tabular}{|c|c|c|c|}
\hline Alternatives & Direct ranking & Inverse ranking & Intermediate ranking $^{1^{\text {st }}}$ \\
\hline \hline BSP & $1^{\text {st }}$ & $1^{\text {st }}$ & $2^{\text {nd }}$ \\
\hline ASP & $2^{\text {nd }}$ & $2^{\text {nd }}$ & 3 rd \\
\hline CSP & $3^{\text {rd }}$ & 4 th & 5 th \\
\hline DSP & 6 th & 5 th & $3^{\text {rd }}$ \\
\hline BCH & 4 th & $3^{\text {rd }}$ & 4 th \\
\hline CCH & 5 th & 5 th & \\
\hline
\end{tabular}

methods is very similar. There is only variation in the alternative CSP, which is in 4th place with the thresholds set directly by the decision maker, and in 3rd place using FAHP thresholds.

The results were discussed with the Purchasing Manager of the company, who said that the results obtained agree with the behaviour desired by the company, that is, to have a long-term relationship with supplier BSP, which is in 1st place. It can also be seen that supplier $\mathrm{BCH}$ is in 3rd place. This position is very favourable for the aims of the company with regard to a future increase in international operations as the supplier is in Asia. It is also clear that $\mathrm{CCH}$ and DSP are suppliers which are definitely of no interest to the organization and, they can be removed from the list of suppliers to be approached in the future.

In conclusion, the decision maker believes that the results of the study are relevant and intends in the future to maintain long-term relations with one or two suppliers, which would be BSP and $\mathrm{BCH}$.

A sensitivity analysis was performed, slightly altering the concordance and discordance thresholds, and showed that there are no changes in the position 
of the top three alternatives, proving the robustness of the method.

\section{CONCLUSIONS}

This research shows how the application of multicriteria techniques can efficiently resolve real problems in organizations. In this case ELECTRE II and ELECTRE II combined with Fuzzy AHP were used, so as to obtain the benefits inherent in each of the techniques. In the case of Fuzzy AHP, it was used to set concordance and discordance thresholds where there was considerable uncertainty in the evaluation. ELECTRE II is a technique that can easily be understood by managers, who have the task of accepting the proposed solution, and is also a noncompensatory technique set in a fuzzy environment.

In future work the intention is to apply other muticriteria decision techniques such as PROMETHEE in a fuzzy environment, and to compare the results.

\section{REFERENCES}

[1] Chen CT, Lin CT, Huang SF. A fuzzy approach for supplier evaluation and selection in supply chain management. Int $J$ Prod Econ 2006; 102(2): 289-301. http://dx.doi.org/10.1016/j.ijpe.2005.03.009

[2] Willis HT, Huston RC, Pohlkamp F. Evaluation measures of just in time supplier performance. Production and Inventory Management Journal 1993; 34(2): 1-5.

[3] Xia W, Wu Z. Supplier selection with multiple criteria in volume discount environments. Omega 2007; 35: 494-504. http://dx.doi.org/10.1016/j.omega.2005.09.002

[4] De Boer L, Labro E, Molrlacchi P. A review of methods supporting supplier selection. European Journal of Purchasing \& Supply Management 2001; 7: 75-89. http://dx.doi.org/10.1016/S0969-7012(00)00028-9

[5] Chamodrakas I, Batis D, Martakos D. Supplier selection in electronic marketplaces using satisficing and fuzzy AHP. Expert Syst Appl 2010; 37: 490-498.

http://dx.doi.org/10.1016/j.eswa.2009.05.043

[6] Rodrigues F, Osiro L, Ribeiro LC. A comparison between Fuzzy AHP and Fuzzy TOPSIS methods to supplier selection. Applied Soft Computing 2014; 21: 194-209. http://dx.doi.org/10.1016/j.asoc.2014.03.014

[7] Munda G, Nijkamp P, Rietveld P. Qualitative multicriteria evaluation for environmental management. Ecol Econ 1994; 10: $97-112$ http://dx.doi.org/10.1016/0921-8009(94)90002-7

[8] Huang IB, Keisler J, Linkov I. Multi-criteria decision analysis in environmental sciences: Ten years of applications and trends. Science of the Total Environment 2011; 409: 35783594. http://dx.doi.org/10.1016/j.scitotenv.2011.06.022

[9] Deng $\mathrm{X}, \mathrm{Hu} \mathrm{Y}$, Deng $\mathrm{Y}$, Mahadevan S. Supplier selection using AHP methodology extended by $D$ numbers. Expert Syst Appl 2014; 41: 156-167.

http://dx.doi.org/10.1016/j.eswa.2013.07.018

[10] Sonmez M. A review and critique of supplier selection process and practices. Occasional Paper, 2006:1.
Loughborough: Business School, Loughborough. Available from: https://dspace.lboro.ac.uk/dspace-jspui/handle/2134/ 2160.

[11] De Boer L, van der Wegen L. Practice and promise of formal supplier selection: a study of four empirical cases. Journal of Purchasing \& Supply Management 2003; 9: 109-118. http://dx.doi.org/10.1016/S1478-4092(03)00018-9

[12] Chai J, Liu JNK, Ngai EWT. Application of decision-making techniques in supplier selection: A systematic review of literature. Expert Syst Appl 2013; 40(10): 3872-3885. http://dx.doi.org/10.1016/i.eswa.2012.12.040

[13] Kar AK. Revisiting the supplier selection problem: An integrated approach for group decision support. Expert Syst Appl 2014; 41: 2762-2771.

[14] Narasimhan R. An analytic approach to supplier selection. Journal of Purchasing and Supply Management 1983; 1(1): 27-32.

[15] Muralidharan C, Anantharaman N, Deshmukh SG. A multicriteria group decision-making model for supplier rating. Journal of Supply Chain Management 2002; 38: 22-33.

http://dx.doi.org/10.1111/j.1745-493X.2002.tb00140.x

[16] Chan FTS. Interactive selection model for supplier selection process: An analytical hierarchy process approach. Int J Prod Res 2003; 41: 3549-3579. http://dx.doi.org/10.1080/0020754031000138358

[17] Chan FTS, Chan HK. Development of the supplier selection model - A case study in the advanced technology industry. Journal of Engineering Manufacture 2004; 218: 1807-1824. http://dx.doi.org/10.1177/095440540421801213

[18] Tahriri F, Osman MR, Ali A, Yusuff RM, Esfandiary A. AHP approach for supplier evaluation and selection in a steel manufacturing Company. Journal of Industrial Engineering Management 2008; 1(02): 54-76. http://dx.doi.org/10.3926/jiem.2008.v1n2.p54-76

[19] Özkan B, Başlıgil H, Şahin N. Supplier Selection Using Analytic Hierarchy Process: An Application From Turkey, Proceedings of the World Congress on Engineering $2011 \mathrm{Vol}$ II WCE 2011, July 6 - 8, London, UK, 2011.

[20] Rajesh G, Malliga P. Supplier Selection Based on AHP QFD Methodology. Procedia Engineering 2013; 64: 1283-1292. http://dx.doi.org/10.1016/j.proeng.2013.09.209

[21] Rajat MV, Vinay AS. Supplier selection using social sustainability: AHP based approach in India. International Strategic Management Review 2014; 2: 98-112. http://dx.doi.org/10.1016/j.ism.2014.10.003

[22] Gonzalez-Prida V, Gómez J, Crespo A. Practical application of an Analytic Hierarchy Process for the improvement of the warranty management. Journal of Quality in Maintenance Engineering 2011; 17(2): 163-182.

http://dx.doi.org/10.1108/13552511111134592

[23] González-Prida V, Barberá L, Viveros P, Crespo A. Dynamic Analytic Hierarchy Process: AHP method adapted to a changing environment. Journal of Manufacturing Technology Management 2014; 25(4): 457-475.

http://dx.doi.org/10.1108/JMTM-03-2013-0030

[24] González-Prida V, Crespo Márquez A. After-sales Service of Engineering Industrial Assets: A Reference Framework for Warranty Management. Cham, Switzerland: Springer Science+Business Media 2014 . http://dx.doi.org/10.1007/978-3-319-03710-3

[25] Dulmin R, Mininno V. Supplier selection using a multi-criteria decision aid method. Journal of Purchasing \& Supply Management 2003; 9(4): 177-187. http://dx.doi.org/10.1016/S1478-4092(03)00032-3

[26] De Boer L, van der Wegen L, Telgen J. Outranking methods in support of supplier selection. European Journal of Purchasing \& Supply Management 1998; 4: 109-118. http://dx.doi.org/10.1016/S0969-7012(97)00034-8 
[27] Roy B. ELECTRE III: Un Algorithme de classements fondé sur une représentation floue des préférences en présence de critères multiples. Cahiers du Centre d'Etudes de Recherche Opérationnelle 1978; 20(1): 3-24.

[28] Duckstein L, Gershon M. Multicriterion analysis of a vegetation management problem using ELECTRE II. Appl Math Model 1983; 7(4): 254-261. http://dx.doi.org/10.1016/0307-904X(83)90078-1

[29] Hokkanen JP, Salminen E, Ettala RM. The choice of a solid waste management system using the Electre II decision-aid method. Waste Manage Res 1995; 13(2): 175-193. http://dx.doi.org/10.1177/0734242X9501300207

[30] Huang WC, Chen $\mathrm{CH}$. Using the ELECTRE II method to apply and analyze the differentiation theory. Proceedings of the Eastern Asia Society for Transportation Studies 2005; 5: 2237-2249.

[31] Armaghan N, Renaud J. An application of multi-criteria decision aids models for Case-Based Reasoning. Inform Sciences 2012; 210: 55-66. http://dx.doi.org/10.1016/j.ins.2012.04.033

[32] Huang D, Ke L. Application of ELECTRE-II on bid evaluation in construction engineering. Proceedings of the IEEE Fifth International Conference on Advanced Computational Intelligence (ICACI); 2012: Nanjing; 2012: p. 816-819. http://dx.doi.org/10.1109/icaci.2012.6463282

[33] Jun D, Tian-tian F, Yi-sheng Y, Yu M. Macro-site selection of wind/solar hybrid power station based on ELECTRE-II. Renewable and Sustainable Energy Reviews 2014; 35: 194204. http://dx.doi.org/10.1016/j.rser.2014.04.005

[34] Hatami-Marbini A, Tavana M. An extension of the Electre I method for group decision-making under a fuzzy environment. Omega 2011; 39: 373-386.

http://dx.doi.org/10.1016/j.omega.2010.09.001

[35] Chen TY. An ELECTRE-based outranking method for multiple criteria group decision making using interval type-2 fuzzy sets. Inform Sciences 2014; 263: 1-21. http://dx.doi.org/10.1016/j.ins.2013.12.012

[36] Almeida AT. Multicriteria decision model for outsourcing contracts selection based on utility function and ELECTRE method. Computers \& Operations Research 2007; 34(12): 3569-3574. http://dx.doi.org/10.1016/j.cor.2006.01.003

[37] Montazer GA, Saremi, HQ, Ramezani M. Design a new mixed expert decision aiding system using fuzzy ELECTRE III method for vendor selection. Expert Syst Appl 2009; 36(8): 10837-10847.

http://dx.doi.org/10.1016/j.eswa.2009.01.019
[38] Sevkli M. An application of the fuzzy ELECTRE method for supplier selection. Int J Prod Res 2010; 48(12): 3393-3405. http://dx.doi.org/10.1080/00207540902814355

[39] Liu P, Zhang X. Research on the supplier selection of a supply chain based on entropy weight and improved ELECTRE-III method. Int J Prod Res 2011; 49(3): 637-646. http://dx.doi.org/10.1080/00207540903490171

[40] Gómez A, Carnero MC. Selection of a Computerised Maintenance Management System: A case study in a Health Regional Service. Prod Plan Control 2011; 22(4): 426-436. http://dx.doi.org/10.1080/09537287.2010.500455

[41] Behzadian M, Kazemzadeh RB, Albadvi A, Aghdasi M. PROMETHEE: A comprehensive literature review on methodologies and applications. Eur J Oper Res 2010; 200(1): 198-215. http://dx.doi.org/10.1016/i.ejor.2009.01.021

[42] Araz C, Ozkarahan I. Supplier evaluation and management system for strategic sourcing based on a new multicriteria sorting procedure. Int J Prod Econ 2007; 106: 585-606. http://dx.doi.org/10.1016/j.ijpe.2006.08.008

[43] Araz C, Ozfirat PM, Ozkarahan I. An integrated multicriteria decision-making methodology for outsourcing management Computers \& Operations Research 2007; 34(12): 3738-3756. http://dx.doi.org/10.1016/i.cor.2006.01.014

[44] Govindan K, Jepsen MB. ELECTRE: A comprehensive literature review on methodologies and applications. Eur $\mathrm{J}$ Oper Res 2016; 250(1): 1-29. http://dx.doi.org/10.1016/i.ejor.2015.07.019

[45] Roy B, Bertier P. La méthode ELECTRE II: une aplication au mediaplanning. Operational Research 1973; 72: 291-302.

[46] Leal C, Sánchez-Apellániz M, Roldán JL, Vázquez AE. Decisiones empresariales con criterios múltiples. Madrid: Ediciones Pirámide 1995.

[47] Romero C. Teoría de la decisión multicriterio: conceptos, técnicas y aplicaciones. Madrid: Alianza Editorial 1993.

[48] Figueira, J, Roy B, Mousseau V. ELECTRE methods. In Figueira J, Greco S, Ehrgott M. (Eds.), Multiple Criteria Decision Analysis: State of the Art Surveys, pp. 133162. New York: Springer Science 2005.

[49] Romero C. Analysis of the multicriteria decisions. Madrid: Isdefe 1996.

[50] Chang DY. Applications of the extent analysis method on fuzzy AHP. Eur J Oper Res 1996; 95: 649-655. http://dx.doi.org/10.1016/0377-2217(95)00300-2

[51] Kaufmann A, Gupta MM. Fuzzy Mathematical Models in Engineering and Management Science. Amsterdam: North Holland 1988.

Received on 18-12-2015

(C) 2016 Carnero and López; Licensee Lifescience Global.

This is an open access article licensed under the terms of the Creative Commons Attribution Non-Commercial License (http://creativecommons.org/licenses/by-nc/3.0/) which permits unrestricted, non-commercial use, distribution and reproduction in any medium, provided the work is properly cited. 